\title{
Demographic assessment of the Dalmatian dog - effective population size, linkage disequilibrium and inbreeding coefficients
}

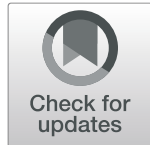

Danae Vasiliadis, Julia Metzger and Ottmar Distl

\begin{abstract}
Background: The calculation of demographic measures is a useful tool for evaluating the genomic architecture of dog breeds and enables ranking dog breeds in terms of genetic diversity. To achieve this for the German Dalmatian dog population, 307 purebred animals of this breed were genotyped on the Illumina Canine high density BeadChip. The analysis of pedigree-based inbreeding was performed based on a pedigree with 25,761 dogs including the genotyped dogs.

Results: The effective population size derived from squared correlation coefficients between SNP alleles $\left(r^{2}\right)$ was 69. The maximum value of $r^{2}$ was 0.56 , resulting in a $50 \%$ decay value of 0.28 at a marker distance of $37.5 \mathrm{~kb}$. The effective population size calculated from pedigree data using individual increase in inbreeding over equivalent generations was 116. The pedigree inbreeding coefficient was 0.026 . The genomic inbreeding coefficient based on the length of runs of homozygosity $(\mathrm{ROH})$ was calculated for seven length categories of $\mathrm{ROH}$ s, and ranged from 0.08 to 0.28 . The fixation coefficients $F_{\text {IS_PED }}$ and $F_{\text {IS_GENO }}$ were at 0.017 and 0.004 . PANTHER statistical overrepresentation analysis of genes located in consensus $\mathrm{ROH}$ s revealed highly underrepresented biological processes in $50 \%$ of the investigated dogs. One of those is the 0.28 fold enriched "immune response", which might be associated to the high prevalence of allergic dermatitis in the breed. Candidate genes for congenital sensorineural deafness (CCSD, a highly prevalent disease in the Dalmatian) were discovered in consensus ROHs.

Conclusions: The fast decay of $r^{2}$ and the moderate inbreeding coefficients indicate that the German Dalmatian dog population is rather diverse. Pedigree- and genomic-based inbreeding measures were highly correlated and therefore prove good reliability for the given population. Analyses of consensus ROHs with genes coding for deafness and other breed-defining traits, such as hyperuricosuria, indicate that those $\mathrm{ROH}$ became fixed in the Dalmatian population about 500 years ago. In case of the Dalmatian dog, a ROH of 40 SNPs length is enough to investigate signatures of selection (e.g. the ROH with the fixed hyperuricosuria mutation) as far back as the breed formation point approximately 500 years ago.
\end{abstract}

Keywords: Dalmatian, Demography, Inbreeding, Diversity, Runs of homozygosity

\footnotetext{
* Correspondence: Ottmar.Distl@tiho-hannover.de

Institute of Animal Breeding and Genetics, University of Veterinary Medicine Hannover, Foundation, 30559 Hannover, Germany
} 


\section{Plain English summary}

Dalmatian dogs are widely known for their uniquely spotted coat. The sporty, medium sized dog was originally bred as a carriage and fire wagon dog and is now a versatile companion animal. Dalmatians are a dog breed with a high prevalence of canine congenital sensorineural deafness (CCSD). It is necessary to combat genetic diseases of purebred dogs, including the Dalmatian, to increase animal welfare. To achieve this, it is useful to gain an insight in the genomic architecture of the breed, to assess whether diseases could stem from increased inbreeding, selection for particular traits or accidental enriched deleterious mutations. With pedigree analyses, one can also identify ancestors with many offspring. An overuse of popular breeding animals can lead to increased inbreeding and loss of genetic diversity in the following generations. This phenomenon is common in dog breeding and called the "popular sire effect". In this study, we aimed to gain an insight into the demography of the Dalmatian dog breed. We calculated inbreeding coefficients from pedigree and genomic data. The pedigree encompassed 25,761 dogs in total and the genomic data were obtained from genotyping 307 Dalmatians on a single nucleotide polymorphism (SNP) array. Pedigree analysis revealed a mean inbreeding coefficient of 0.026 and an effective population size of 116. From the SNP array data, the genomic inbreeding coefficient was derived and ranged from 0.08 to 0.28 . The effective population size amounted to 69. In this study, we reinforced that inbreeding estimation using genomic data tends to be more accurate than by pedigree analysis. Both approaches were highly correlated, though and therefore prove good reliability of both methods. The Dalmatian was found to be a rather genetically diverse dog breed. Investigations of runs of homozygosity (regions with loss of genetic variation) revealed four deafness candidate genes, which might indicate a connection to the high prevalence of CCSD. Those genes therefore deserve further investigation for their contribution to CCSD.

\section{Background}

The issues of inbreeding and inherited diseases of purebred dogs have steadily gained more public recognition in the recent years [1]. To combat those issues and improve the animal health it is necessary to gain solid knowledge of the genomic architecture of the particular breed [2]. Highdensity single nucleotide polymorphism (SNP) arrays are tools for genetic diversity assessment, as they provide genomic data necessary for the calculation of demographic measures. In this study, we aimed to gain an insight into the demography of the Dalmatian dog breed using pedigree and genome-wide SNP data from highly dense arrays.

Other studies have already focused on the demography of other dog breeds using various data sources. For example, with SNP array data, a high amount of withinbreed genetic differentiation was found in Labrador Retrievers. The total length of runs of homozygosity $(\mathrm{ROH})$ was highly correlated with the pedigree based inbreeding coefficient $\left(\mathrm{F}_{\mathrm{PED}}\right)$ [3]. Further work on the dog breeds Golden Retriever, Rottweiler and Newfoundland focused on the linkage disequilibrium (LD). The 50\% decay value of $r^{2}$ (squared correlation coefficients between SNP alleles) was used to measure the variation of LD between breeds [4]. The Lundehund exhibited an extraordinarily high homozygosity indicative for a highly inbred breed. The low genetic variability was reflected in numerous, extensive ROHs, as well as a very low effective population size $\left(\mathrm{N}_{\mathrm{e}}\right)$, and a slow decay of $r^{2}$. Recent efforts in outcrossing the breed were reflected in visible changes in the effective population size [5]. In the Korean aboriginal Sapsaree dog, SNP array and pedigree data were used to estimate $\mathrm{N}_{\mathrm{e}}$. The declining $\mathrm{N}_{\mathrm{e}}$-values over the recent generations, demonstrate the need for improved breeding strategies to preserve genetic variability in the Sapsaree dog [6]. For the Nova Scotia Duck Tolling Retriever and Lancashire Heeler dog, their respective effective population sizes were estimated. From the analysis of those pedigree data was concluded that different breeding programs are necessary to increase the genetic variation, namely outcrossing with other breeds for the Nova Scotia Duck Tolling Retriever [7]. Already available data for the Dalmatian are a pedigree inbreeding coefficient of 0.024 and a realized effective population size of 120 [2]. An overview of the analyzed data and results obtained with the studies above is given in Table 1 .

As demonstrated above, the calculation of demographic measures and genetic variability from pedigree data and SNP arrays has been proven a useful tool for critically rethinking the breeding strategies of purebred dogs. While inbreeding measures derived from SNP array data more accurately depict, amongst other, the individual inbreeding [8], pedigree data can provide valuable insights into distant animals where no DNA samples were obtained, and therefore into the population history. No study specifically addressing the demography of the Dalmatian has been published yet. Therefore, the objectives of the present study were to estimate the effective population size $\left(\mathrm{N}_{\mathrm{e}}\right)$ of the Dalmatian from data on linkage disequilibria (LD) obtained by genotyping 307 Dalmatians with the Illumina Canine high density BeadChip (Illumina Inc., San Diego, CA, USA) and genealogical data, as well as identifying runs of homozygosity $(\mathrm{ROH})$ as regions with local loss of genetic variation. We then identified the genes located in those consensus ROHs. Inbreeding coefficients were calculated based on pedigree data $\left(\mathrm{F}_{\mathrm{PED}}\right.$ and fixation coefficient $\mathrm{F}_{\mathrm{IS}}$ ) and genotype information (genomic inbreeding coefficient, $\mathrm{F}_{\mathrm{ROH}}$ and $\mathrm{F}_{\mathrm{IS}}$ ) to compare the results of these 
Table 1 Overview of results and methods for demography studies of dog breeds. Demographic measures and data sources of further demographic assessments are stated

\begin{tabular}{|c|c|c|c|c|c|c|c|c|c|}
\hline Reference & Dog breed & $\begin{array}{l}\text { Number of } \\
\text { genotyped } \\
\text { animals }\end{array}$ & $\begin{array}{l}\text { Number } \\
\text { of animals } \\
\text { in pedigree }\end{array}$ & $\begin{array}{l}\text { Mean } \\
\text { pedigree- } \\
\text { based } \\
\text { inbreeding } \\
\text { coefficient } \\
\text { F PED }\end{array}$ & $\begin{array}{l}\text { Pedigree- } \\
\text { based effective } \\
\text { population } \\
\text { size }\left(N_{e}\right)\end{array}$ & $\begin{array}{l}\text { Genomic- } \\
\text { based } N_{e}\end{array}$ & $\begin{array}{l}\text { Mean genomic- } \\
\text { based inbreeding } \\
\text { coefficient } \mathrm{F}_{\mathrm{ROH}} \\
\text { (ROH length) }\end{array}$ & $\begin{array}{l}50 \% \text { decay } \\
\text { value of } r^{2}\end{array}$ & $\begin{array}{l}\text { Pearson correlation } \\
\text { coefficient of } F_{P E D} \\
\text { and } F_{R O H}\end{array}$ \\
\hline $\begin{array}{l}\text { Wiener et al. } \\
2017 \text { [3] }\end{array}$ & $\begin{array}{l}\text { Labrador } \\
\text { Retriever }\end{array}$ & 1008 & 25,526 & 0.0702 & $55-82$ & $74-88$ & 0.21 (100 SNPs) & & 0.78 \\
\hline \multirow[t]{3}{*}{$\begin{array}{l}\text { Stern et al. } \\
2013 \text { [4] }\end{array}$} & $\begin{array}{l}\text { Golden } \\
\text { Retriever }\end{array}$ & 24 & & & & & & $\begin{array}{l}715 \mathrm{~kb} \\
\left(r^{2}=0.243\right)\end{array}$ & \\
\hline & Rottweiler & 28 & & & & & & $\begin{array}{l}834 \mathrm{~kb} \\
\left(r^{2}=0.241\right)\end{array}$ & \\
\hline & Newfoundland & 23 & & & & & & $\begin{array}{l}344 \mathrm{~kb} \\
\left(\mathrm{r} 2^{2}=0.243\right)\end{array}$ & \\
\hline $\begin{array}{l}\text { Pfahler et al. } \\
2015 \text { [5] }\end{array}$ & Lundehund & 28 & & 0.1 & & 12 & $\begin{array}{l}0.87 \text { (50 SNPs) } \\
0.87 \text { (65 SNPs) } \\
0.81 \text { (358 SNPs) }\end{array}$ & & $0.11\left(\mathrm{~F}_{\mathrm{ROH}} 358 \mathrm{~S} \mathrm{NP}\right)$ \\
\hline $\begin{array}{l}\text { Alam et al. } \\
2012[6]\end{array}$ & Sapsaree & 183 & 8264 & 0.1 & $16-51$ & $\begin{array}{l}64-75 \text { (5 } \\
\text { generations } \\
\text { ago) }\end{array}$ & & & \\
\hline \multirow[t]{2}{*}{$\begin{array}{l}\text { Mäki } 2010 \\
\text { [7] }\end{array}$} & $\begin{array}{l}\text { Nova Scotia } \\
\text { Duck Tolling } \\
\text { Retriever }\end{array}$ & & 28,668 & 0.26 & $\begin{array}{l}18 \text { (realised } \\
\mathrm{N}_{\mathrm{e}} \text { ) }\end{array}$ & & & & \\
\hline & $\begin{array}{l}\text { Lancashire Heeler } \\
\text { dog }\end{array}$ & & 4782 & 0.1 & $\begin{array}{l}28 \text { (realised } \\
N_{e} \text { ) }\end{array}$ & & & & \\
\hline $\begin{array}{l}\text { Leroy et al. } \\
2009 \text { [2] }\end{array}$ & $\begin{array}{l}\text { Dalmatian } \\
\text { (among } 60 \\
\text { other) }\end{array}$ & 20 & 17,778 & 0.024 & $\begin{array}{l}120 \text { (realised } \\
N_{e} \text { ) }\end{array}$ & & & & \\
\hline
\end{tabular}

different methods for this population. This study enables ranking the Dalmatian with other dog breeds in terms of genetic diversity.

\section{Results}

Inbreeding measures by pedigree analysis

We identified highly inbred matings in the whole population. There were $31(0.12 \%)$ matings between full siblings, $474(1.84 \%)$ half sibling matings and $25(0.1 \%)$ parent-offspring pairings. The inbreeding measures were calculated for a reference population, which is comprised of all animals born in the years 1995 to 2015 including the genotyped dogs, and for the genotyped dogs in separate. The period from 1995 to 2015 was chosen because it encompasses the birth years of the genotyped dogs. The equivalent complete generations were 7.46 for the reference population and 7.49 for the Beadchip sample. The realized $\mathrm{N}_{\mathrm{e}}$ was 92.87 for the reference

Table 2 Results of inbreeding measures calculation. The results are stated separately for the genotyped animals and for the reference population with all animals in the pedigree of the same birth years as the genotyped animals. The complete pedigree size amounts to 25.761 animals

\begin{tabular}{lll}
\hline & Population born from 1995 to 2015 & Beadchip Sample \\
\hline Number of animals & 18,061 & 313 \\
Mean F & 0.035 & 0.026 \\
Mean equivalent generations & 7.46 & 7.49 \\
Mean FIS & 0.016 & 0.017 \\
Number of ancestors & 446 & 181 \\
Effective number of ancestors & 59 & 55 \\
Number of ancestors explaining 50\% of genetic diversity & 22 & 20 \\
Number of founders & 797 & 498 \\
Effective number of founders & 158 & 135 \\
$N_{\mathrm{e}}$ by individual increase in inbreeding (realized $\mathrm{N}_{\mathrm{e}}$ ) & $92.87 \pm 13.29$ & $116.16 \pm 14.93$ \\
Mean generation interval in years & 4.33 & 4.54 \\
\hline
\end{tabular}


population and 116.16 for the Beadchip sample. The $\mathrm{N}_{\mathrm{e}}$ over the paired increase in coancestry amounted to 70.93 for the Beadchip sample (Table 2). The mean $\mathrm{F}_{\text {IS_PED }}$ for the Beadchip sample was 0.017 and 0.016 for the reference population. For the reference population the mean inbreeding coefficient $\mathrm{F}_{\mathrm{PED}}$ amounted to 0.035 , and the $F_{P E D}$ for the Beadchip sample was at 0.026 ranging from 0 to 0.347 . The average $F_{P E D}$ per generation is listed in Table 3. For the Beadchip sample we identified 181 ancestors, with an effective number of ancestors $\left(f_{a}\right)$ of 55. There were 498 founders, and the effective number of founders $f_{e}$ was 135 . In the reference population were 446 ancestors, 59 effective ancestors, 797 founders and 158 effective founders. The generation interval lengths for the reference population (and Beadchip sample) for the four different pathways were: sire to dam 4.32 (4.44) years, dam to sire 4.24 (4.55) years, sire to sire 4.51 (5.12) years and dam to dam 4.29 (4.22) years. The mean generation interval was 4.33 (4.54) years.

Table 3 Average inbreeding coefficient per generation. The average $F_{P E D}$ per generation was calculated over the whole pedigree. Generation 0 is the founder generation and generation 24 the youngest generation

\begin{tabular}{|c|c|c|}
\hline Generations & Number of animals & average FPED \\
\hline 0 & 1147 & 0 \\
\hline 1 & 352 & 0 \\
\hline 2 & 198 & 0.001 \\
\hline 3 & 138 & 0.008 \\
\hline 4 & 127 & 0.024 \\
\hline 5 & 149 & 0.025 \\
\hline 6 & 130 & 0.017 \\
\hline 7 & 137 & 0.025 \\
\hline 8 & 141 & 0.033 \\
\hline 9 & 164 & 0.034 \\
\hline 10 & 222 & 0.038 \\
\hline 11 & 316 & 0.033 \\
\hline 12 & 482 & 0.033 \\
\hline 13 & 1008 & 0.033 \\
\hline 14 & 2134 & 0.030 \\
\hline 15 & 3366 & 0.038 \\
\hline 16 & 3178 & 0.027 \\
\hline 17 & 2803 & 0.031 \\
\hline 18 & 2397 & 0.033 \\
\hline 19 & 2500 & 0.038 \\
\hline 20 & 2411 & 0.036 \\
\hline 21 & 1390 & 0.049 \\
\hline 22 & 718 & 0.054 \\
\hline 23 & 124 & 0.132 \\
\hline 24 & 29 & 0.178 \\
\hline
\end{tabular}

\section{Inbreeding measures from SNP array data}

The mean $r^{2}$ in the Dalmatian was 0.56 at its maximum value (Fig. 1). The $\mathrm{LD}$ decreased to values below $r^{2}=$ 0.11 for SNPs $1 \mathrm{Mb}$ apart (Fig. S1). The $50 \%$ decay value of $r^{2}$ from its maximum was 0.28 , corresponding to a mean marker distance of $37.5 \mathrm{~kb}$. $\mathrm{N}_{\mathrm{e}}$ was calculated for the last 50 generations. Between 10 and 4 generations ago, $\mathrm{N}_{\mathrm{e}}$ remained stable at a level of 109 to 104 (Fig. 2). In the very recent generations, $\mathrm{N}_{\mathrm{e}}$ decreased to a value of 69 (Fig. S2). The increase in inbreeding per generation $(\Delta F)$ reached a maximum of 0.007 in the actual generation (Fig. 3). From 50 to 10 generations ago, $\Delta F$ steadily rose from 0.0025 to 0.004 . The mean $\mathrm{F}_{\text {IS GENO -value }}$ was 0.004 and ranged from -0.141 to 0.228 .

The 10- to 358-SNP-thresholds resulted in ROHs of at least 120 to $5012 \mathrm{~kb}$ length. The mean $\mathrm{F}_{\mathrm{ROH} 358 \text { sNP }}$ for all Dalmatians was 0.08 (0.002 to 0.23$)$ and the

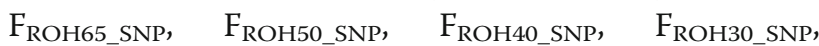
$\mathrm{F}_{\mathrm{ROH} 20 \_\mathrm{SNP}}$ and $\mathrm{F}_{\mathrm{ROH} 10 \text { SNP }}$-values were 0.16 (0.06 to 0.31 ), 0.17 (0.07 to 0.32 ), 0.18 (0.08 to 0.33 ), 0.19 (0.09 to 0.34$), 0.22$ (0.12 to 0.36 ) and 0.28 (0.19 to 0.4 ), respectively. The Pearson correlation coefficient was at 0.675 among the inbreeding coefficients $\mathrm{F}_{\mathrm{PED}}$ and $\mathrm{F}_{\mathrm{IS}-}$ GENO, and correlation coefficients among $\mathrm{F}_{\text {IS_GENO }}$ and $\mathrm{F}_{\mathrm{ROH} 10}$ through $\mathrm{F}_{\mathrm{ROH} 358}$ ranged from 0.81 to 0.917 . Correlations among the different $\mathrm{F}_{\mathrm{ROH}}$ were ranging from 0.81 to 0.99 (Table 4). We identified $13,5,4$ and 1 consensus ROHs for the 10, 20, 30 and 40-SNP thresholds (Table 5). There were 40 genes located in the consensus ROHs, with some genes associated to disease predispositions of the Dalmatian dog (Table 6, Table S1).

\section{PANTHER statistical overrepresentation analysis and functional classification test}

Underrepresented biological processes were identified in the $50 \%$ fixed (ROHs common to $50 \%$ of the genotyped

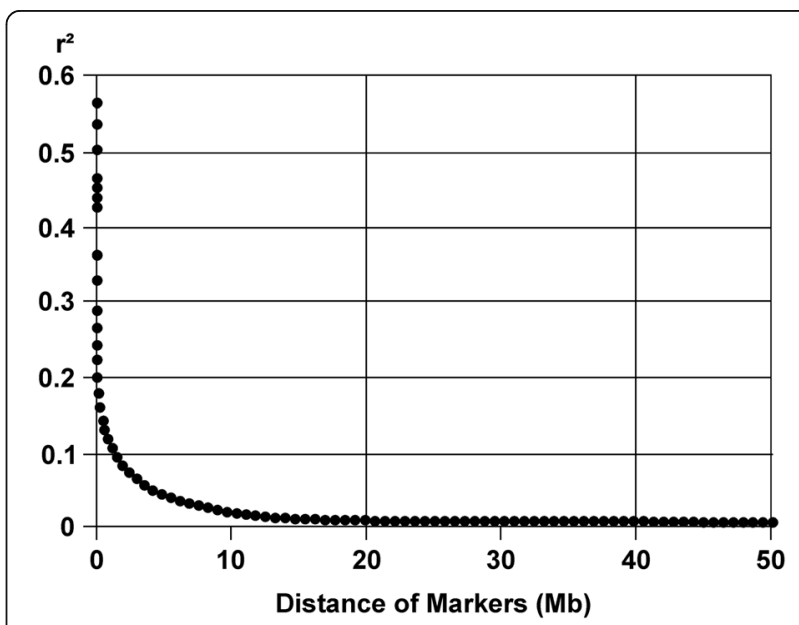

Fig. 1 Decay of linkage disequilibria $\left(r^{2}\right)$ between SNP pairs spanning an increasing distance 


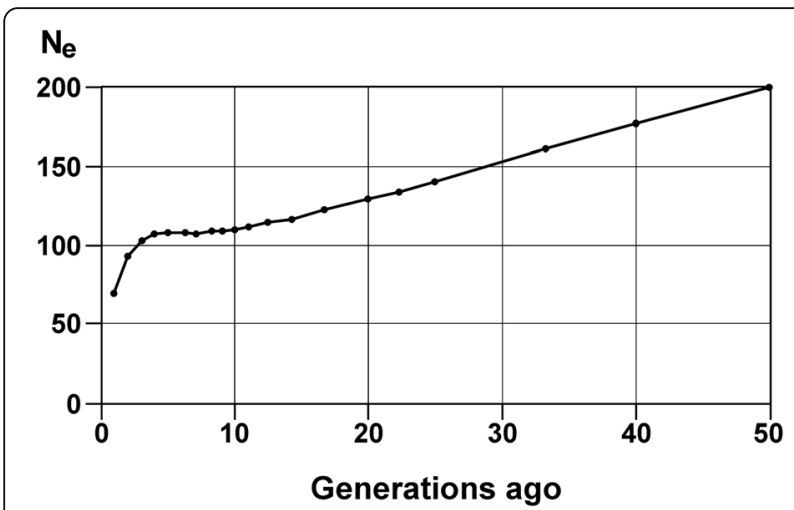

Fig. 2 Ancestral population size of the Dalmatian in the last 50 generations. The effective population size was estimated from the mean $r^{2}$ for the 38 canine autosomes

dogs) 10-SNP ROHs. Most underrepresented were "immune response" (0.28 fold enrichment), "sensory perception of smell" (0.23 fold enrichment) and "sensory perception of chemical stimulus" ( 0.36 fold enrichment) (Table S2). Biological processes that were overrepresented were mainly found in the $75 \%$ fixed 20 -SNP and 30-SNP ROHs, namely "digestive tract mesoderm development" with a 27.46 resp. 35.34 fold enrichment. The genes in the consensus $\mathrm{ROH}$ were mostly assigned to the functional classes "cellular process" and "metabolic process" (Table S3).

\section{Discussion}

The genomic inbreeding coefficient $\mathrm{F}_{\mathrm{ROH}}$ assumes different values depending on the length of the $\mathrm{ROH}$ used for calculation. Therefore, we calculated the $\mathrm{F}_{\mathrm{ROH}}$ over each of the seven $\mathrm{ROH}$ length thresholds in SNPs. Short $\mathrm{ROHs}$ represent inbreeding incidences of distant ancestors, as the homozygous chromosome segments are broken down over time due to the crossing-over in

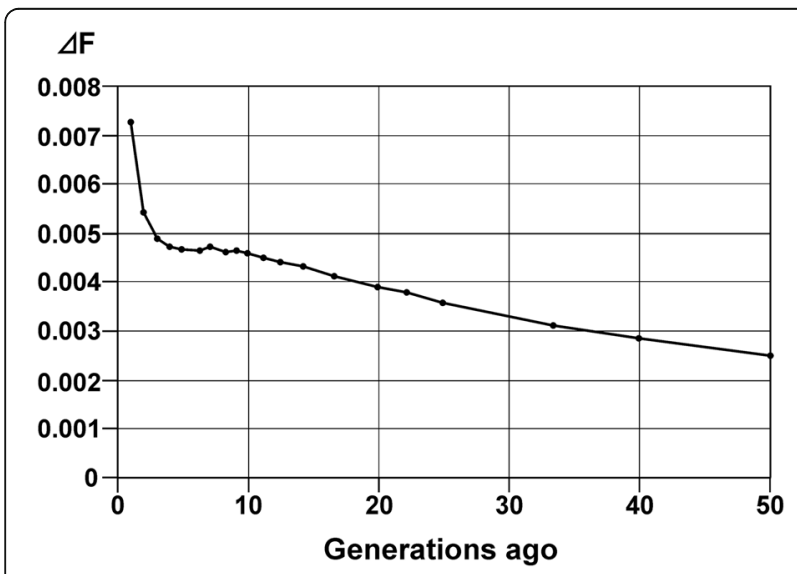

Fig. 3 Average increase in inbreeding $(\Delta F)$ in the Dalmatian for 1 to 50 generations ago meiosis. Consequently, long $\mathrm{ROH}$ are an indication of recent mating of related individuals [9]. Short $\mathrm{ROH}$ are more numerous in the Dalmatian and cover a larger amount of the genome, thus resulting in a higher $\mathrm{F}_{\mathrm{ROH}}$. This was expected as it was previously demonstrated in humans that even in inbred populations, the short $\mathrm{ROH}$ make up the majority of $\mathrm{ROH}$ [9]. The results, namely few detectable long $\mathrm{ROH}$ in the Dalmatian $\left(\mathrm{F}_{\mathrm{ROH} 358}=\right.$ 0.08) indicate that there are only few recent inbreeding incidences. Choosing shorter $\mathrm{ROH}$ for inbreeding calculations shows that there are probably more distant inbreeding incidences $\left(\mathrm{F}_{\mathrm{ROH} 20}=0.22\right)$.

The estimation of inbreeding by pedigree analysis is subjected to the completeness and quality of pedigree data. Missing family members as well as the assumed unrelatedness of founders lead to a bias of $F_{\text {PED }}$ to lower values [10-12]. Additionally, the $\mathrm{F}_{\mathrm{PED}}$ cannot reliably predict the actual proportion of IBD genome that related individuals share. The actual amount of the genome that is identical by descent (IBD) varies around the value predicted by pedigree data because of Mendelian segregation [13-16]. Thus the estimation of inbreeding by $F_{\mathrm{ROH}}$ is more accurate than by $F_{P E D}$ [8]. This is demonstrated here by an almost 10 times higher $\mathrm{F}_{\mathrm{ROH}}$ of a moderate SNP length threshold $\left(\mathrm{F}_{\mathrm{ROH} 20}=0.22\right)$ than $\mathrm{F}_{\mathrm{PED}}(0.026)$. The mean $F_{P E D}$ for the reference population was 0.035 . It appears that the genotyped Dalmatians were on average less inbred than the rest of the population. This is plausible since we chose distantly related and not highly inbred Dalmatians for genotyping. The few highly inbred matings were thus not included in the genomic analyses and may have contributed to a higher $\mathrm{F}_{\mathrm{PED}}$ for the total reference population. Nonetheless the Dalmatians chosen for genotyping are representative for the population, as they were collected from the best documented birth years and across all major German Dalmatian breed clubs. Additionally, we compared the average coancestries of the two reference populations. The average coancestry for the Beadchip sample was 0.019 and $0.022 \%$ for the reference population, which are very similar values. The assessment of ancestors and founders also shows that the founders and ancestors from the reference population are sufficiently represented in the Beadchip sample.

The effective population sizes derived from linkage disequilibria showed a significant drop from 102 to 69 in the last three generations. This equals to a rise in the increase in inbreeding from 0.004 per generation to 0.007 per generation. The breakdown of the average $F_{P E D}$ per generation also shows an increase in inbreeding over the last generations. The Food and Agricultural Organization (FAO) of United Nations recommends that in order to maintain fitness in a population, the increase in inbreeding should not exceed $1 \%$ per generation, which equals an 
Table 4 Pearson correlation coefficients. The correlation coefficients with a $P$-value $<0.0001$ between the pedigree inbreeding coefficient $F_{P E D}$, the genomic inbreeding coefficient $F_{R O H}$ over the seven run of homozygosity $(R O H)$ length thresholds, and the fixation coefficient $F_{I S \_G E N O}$ are given

\begin{tabular}{llllllllll}
\hline & $F_{P E D}$ & $F_{\text {IS_GENO }}$ & $F_{\text {ROH10 }}$ & $F_{\text {ROH20 }}$ & $F_{\text {ROH30 }}$ & $F_{\text {ROH40 }}$ & $F_{\text {ROH50 }}$ & $F_{\text {ROH65 }}$ & $F_{\text {ROH358 }}$ \\
\hline$F_{\text {IS_GENO }}$ & 0.675 & 1 & 0.889 & 0.91 & 0.916 & 0.917 & 0.915 & 0.912 & 0.81 \\
$F_{\text {ROH10 }}$ & 0.629 & 0.889 & 1 & 0.991 & 0.986 & 0.985 & 0.981 & 0.972 & 0.858 \\
$F_{\text {ROH20 }}$ & 0.639 & 0.91 & 0.991 & 1 & 0.995 & 0.994 & 0.992 & 0.988 & 0.878 \\
$F_{\text {ROH30 }}$ & 0.643 & 0.916 & 0.986 & 0.995 & 1 & 0.999 & 0.995 & 0.991 & 0.879 \\
$F_{\text {ROH40 }}$ & 0.645 & 0.917 & 0.985 & 0.994 & 0.999 & 1 & 0.996 & 0.992 & 0.882 \\
$F_{\text {ROH50 }}$ & 0.641 & 0.915 & 0.981 & 0.992 & 0.995 & 0.996 & 1 & 0.995 & 0.891 \\
$F_{\text {ROH65 }}$ & 0.637 & 0.912 & 0.972 & 0.988 & 0.991 & 0.992 & 0.995 & 1 & 0.902 \\
$F_{\text {ROH358 }}$ & 0.589 & 0.81 & 0.858 & 0.878 & 0.879 & 0.882 & 0.891 & 0.902 & 1 \\
\hline
\end{tabular}

effective population size of 50 [17]. The Dalmatian is still below that critical threshold, but the steep rise in $\Delta \mathrm{F}$ is a cause to concern if the trend continues. Thus, the development of the increase in inbreeding should be monitored further, to confirm or reject the hypothesis of rapidly increasing inbreeding. The results of the pedigree-derived effective population size computation over the individual increase in inbreeding showed high conformity to the one derived from $r^{2}\left(\mathrm{~N}_{\mathrm{e}}\right.$ 116.16). The calculation of $\mathrm{N}_{\mathrm{e}}$ over the paired increase in coancestry showed even more accordance $\left(\mathrm{N}_{\mathrm{e}}\right.$ 70.93). This parameter was calculated additionally, as the $\mathrm{N}_{e}$ over the increase in inbreeding tends to be inaccurate if there is substructure in the population [18], which our $F_{I S}$ value suggests. Nonetheless, both approaches to calculate pedigree $\mathrm{N}_{\mathrm{e}}$ appear appropriate for $\mathrm{N}_{\mathrm{e}}-$ calculation of this and other rather large, welldocumented pedigrees.

\section{Comparison of decay of $r^{2}$ in different dog breeds}

The Dalmatian featured a fast decay of LD. We compared the point of $50 \%$ decay of $r^{2}$ (defined as the point at which $r^{2}$ reaches $50 \%$ of its maximum value) to largesized dog breeds of another study which made use of
SNP array data, too [4]. Golden Retrievers, Rottweilers and Newfoundland dogs had a point of 50\% decay of $r^{2}$ at $r^{2}=0.24$ with corresponding marker distances of 714 $\mathrm{kb}, 833 \mathrm{~kb}$ and $344 \mathrm{~kb}$, respectively. The Dalmatian had a steeper decrease of $r^{2}$ values, reaching the 50\% decay point at a marker distance of $37.5 \mathrm{~kb}$. When we chose the point at which $r^{2}$ reaches 0.24 , we still found a much shorter marker distance of $62.5 \mathrm{~kb}$ than in the other breeds. Another study chose the arbitrary point of $r^{2}=$ 0.2 to compare wolves and domestic dog breeds [19]. Results were distances for $r^{2}=0.2$ from $20 \mathrm{~kb}$ to $>5 \mathrm{Mb}$ in 18 dog breeds, with the Labrador Retriever on the low end and the Bernese Mountain dog on the high end. This places the Dalmatian with an $r^{2}=0.2$ value of 124 $\mathrm{kb}$ on the lower end, too. Breeds with comparable extent of LD in that study were the Saint Bernard with $83 \mathrm{~kb}$ and the Pomeranian with $200 \mathrm{~kb}$. The demographic evaluation of the Sapsaree dog included LD estimation, too [6]. The autosomal-genome-wide values for $r^{2}$ in the Sapsaree dog at a SNP distance of $100 \mathrm{~kb}$ and $5 \mathrm{Mb}$ were $r^{2}=0.16$ and $r^{2}=0.1$. In the Dalmatian $r^{2}$ values of 0.16 and 0.1 corresponded to marker distances of $274 \mathrm{~kb}$ and 1.24 Mb. In comparison of those two studies, the low $r^{2}$

Table 5 Overview of the amount and length of runs of homozygosity (ROHs). Seven different length thresholds were set for the calling of runs of homozygosity $(\mathrm{ROH})$. For all thresholds the number and length of detected ROHs per individual and detected consensus ROHS are given, respectively. The mean inbreeding coefficient $F_{\mathrm{ROH}}$ was estimated depending on the different thresholds

\begin{tabular}{|c|c|c|c|c|c|c|c|c|}
\hline \multirow{2}{*}{$\begin{array}{l}\text { Thresholds } \\
\text { Minimum } \\
\text { ROH length in } \\
\text { SNP }\end{array}$} & \multicolumn{4}{|c|}{ All ROHs per individual } & \multicolumn{3}{|c|}{ Consensus ROHs per individual } & \multirow[b]{2}{*}{$\begin{array}{l}\text { Mean } \\
\mathrm{F}_{\mathrm{ROH}}\end{array}$} \\
\hline & $\begin{array}{l}\text { Mean } \\
\text { number of } \\
\text { ROHs }\end{array}$ & $\begin{array}{l}\text { Length of } \\
\text { shortest ROH } \\
\text { (Kb) }\end{array}$ & $\begin{array}{l}\text { Mean length } \\
\text { of } \mathrm{ROH}(\mathrm{Mb})\end{array}$ & $\begin{array}{l}\text { Average cumulative } \\
\text { length of all ROHs } \\
\text { (Mb) }\end{array}$ & $\begin{array}{l}\text { Number of } \\
\text { consensus } \\
\text { ROHs }\end{array}$ & $\begin{array}{l}\text { Mean length of } \\
\text { consensus ROH } \\
\text { (Mb) }\end{array}$ & $\begin{array}{l}\text { Cumulative length of } \\
\text { all consensus ROHs } \\
\text { (Mb) }\end{array}$ & \\
\hline 10 & 1185 & 120 & 0.52 & 619.25 & 13 & 0.23 & 2.93 & 0.28 \\
\hline 20 & 384 & 240 & 1.26 & 486.40 & 5 & 0.4 & 1.99 & 0.22 \\
\hline 30 & 207 & 360 & 2.07 & 428.53 & 4 & 0.4 & 1.6 & 0.19 \\
\hline 40 & 157 & 480 & 2.59 & 407.02 & 1 & 0.67 & 0.67 & 0.18 \\
\hline 50 & 115 & 700 & 3.29 & 379.12 & 0 & 0 & 0 & 0.17 \\
\hline 65 & 94 & 910 & 3.82 & 359.88 & 0 & 0 & 0 & 0.16 \\
\hline 358 & 18 & 5012 & 10.22 & 183.97 & 0 & 0 & 0 & 0.08 \\
\hline
\end{tabular}


Table 6 Disease-associated genes in the consensus ROHs. Disease and disease candidate genes that are located in the consensus $\mathrm{ROH}$ s of the Dalmatians are depicted. Other genes that are located in the 13 consensus $\mathrm{ROH}$ are also given. The start and end of consensus $\mathrm{ROH}$ in base pairs and the length of consensus $\mathrm{ROH}$ in base pairs comply to the detection of consensus $\mathrm{ROH}$ with the 10 SNP threshold

\begin{tabular}{|c|c|c|c|c|c|c|}
\hline Chromosome & Start (bp) & End (bp) & $\begin{array}{l}\text { Length of } \\
\text { consensus } \\
\text { ROH in } \\
\text { beadchip } \\
\text { SNPs }\end{array}$ & $\begin{array}{l}\text { Length of } \\
\text { consensus } \\
\mathrm{ROH} \text { in bp }\end{array}$ & $\begin{array}{l}\text { Genes that are located in } \\
\text { the consensus } \mathrm{ROH}\end{array}$ & $\begin{array}{l}\text { Associated diseases of } \\
\text { those genes }\end{array}$ \\
\hline 1 & $23,754,226$ & $24,443,343$ & 55 & 689.117 & $\begin{array}{l}\text { MEX3C, SMAD4, ELAC1, ME2, } \\
\text { MRO, RFO0001, MC2R, MC5R, } \\
\text { ENSCAFG00000032822 }\end{array}$ & $\begin{array}{l}\text { Glaucoma (SMAD4), } \\
\text { Idiopathic epilepsy (ME2) }\end{array}$ \\
\hline 3 & $67,712,997$ & $67,855,181$ & 13 & 142.184 & $\begin{array}{l}\text { ENSCAFG000000033564, } \\
\text { ENSCAFG00000036945, } \\
\text { ENSCAFG00000037957 }\end{array}$ & - \\
\hline 3 & $67,876,487$ & $68,200,003$ & 29 & 323.516 & $\begin{array}{l}\text { ENSCAFG00000033306, } \\
\text { ENSCAFG00000033607 }\end{array}$ & - \\
\hline 3 & $69,068,007$ & $69,485,604$ & 38 & 417.597 & $\begin{array}{l}\text { CLNK, ZNF518B, SLC2A9, } \\
\text { WDR1, ENSCAFG00000039826, } \\
\text { ENSCAFG00000033935 }\end{array}$ & $\begin{array}{l}\text { Diabetes mellitus, entropion, } \\
\text { hyperuricosuria (SLC2A9) }\end{array}$ \\
\hline 4 & $38,457,632$ & $38,587,643$ & 15 & 130.011 & NSG2, ENSCAFG00000032093 & - \\
\hline 13 & $3,182,619$ & $3,330,775$ & 13 & 148.156 & GRHL2, ENSCAFG00000030800 & Deafness (GRHL2) \\
\hline 13 & $3,490,088$ & $3,550,490$ & 7 & 60.402 & ENSCAFG00000036103 & - \\
\hline 17 & $35,638,035$ & $35,834,516$ & 17 & 196.481 & $\begin{array}{l}\text { BCL2L11, ENSCAFG00000036821, } \\
\text { ENSCAFG00000007091 }\end{array}$ & Deafness (BCL2L11) \\
\hline 17 & $35,861,411$ & $35,861,411$ & 1 & 1 & $\begin{array}{l}\text { ENSCAFG00000035515, } \\
\text { ENSCAFG00000040340 }\end{array}$ & - \\
\hline 17 & $39,631,741$ & $39,800,897$ & 18 & 169.156 & $\begin{array}{l}\text { CAPG, ELMOD3, RETSAT, TCF7L1, } \\
\text { ENSCAFG00000024531 }\end{array}$ & Deafness (ELMOD3) \\
\hline 24 & $15,945,228$ & $16,028,176$ & 7 & 82.948 & SHLD1 & - \\
\hline 24 & $34,585,142$ & $34,731,796$ & 12 & 146.654 & $\begin{array}{l}\text { NCOA3, ENSCAFG00000035729, } \\
\text { ENSCAFG00000010850 }\end{array}$ & - \\
\hline 38 & $11,140,991$ & $11,561,386$ & 36 & 420.395 & USH2A & Deafness \\
\hline
\end{tabular}

values in the Sapsaree dog declined slowly, and started higher but reaches lower values in the Dalmatian. A fast decay of $r^{2}$ indicates a high genetic diversity. In comparison with results from other genotyped dog breeds, the Dalmatian belongs to the more diverse breeds.

The high correlation of $\mathrm{F}_{\mathrm{ROH}}$ to $\mathrm{F}_{\mathrm{PED}}$ throughout all $\mathrm{F}_{\mathrm{ROH}}$ length thresholds indicates that both measures describe the inbreeding load of the individual with good reliability. A good correlation of $\mathrm{F}_{\mathrm{ROH}}$ to $\mathrm{F}_{\mathrm{PED}}$ has already been demonstrated in other studies $[3,20]$. The moderate genomic and pedigree inbreeding coefficients and the fast decay of $r^{2}$, all in relation to comparable breeds, indicate that the Dalmatian belongs to the more diverse breeds. None of the over- or underrepresented biological processes of genes located in consensus $\mathrm{ROH}$ point to the contribution to frequently occurring diseases in the Dalmatian. The underrepresented "immune response" in the $50 \%$ fixed $\mathrm{ROHs}$ might be associated with the high prevalence of allergic dermatitis, though [21].

\section{Analysis of genes located in consensus ROHs}

Fourty genes were identified in $\mathrm{ROHs}$ shared by all genotyped Dalmatians. Among them were four genes associated with deafness [grainyhead like transcription factor 2 (GRHL2), BCL2 like 11 (BCL2L11), ELMO domain containing 3 (ELMOD3), usherin (USH2A)]. With the high prevalence of CCSD in the Dalmatian in mind, those genes could possibly harbor variants contributing to CCSD. From the length of those $\mathrm{ROH}$, the time of origin of the $\mathrm{ROH}$ was estimated. Those consensus ROH were 169.156 to 420.395 bp long, which implies an origin from $\sim 119$ to $\sim 337$ generations ago. With a generation interval of 4.33 years, assuming the generation interval did not change much over the last centuries, this amounts to $\sim 515$ to $\sim 1459$ years ago. Deafnesscontributing variants in small consensus $\mathrm{ROH}$ may explain the widespread occurrence of CCSD in all Dalmatian breeding lines.

Also, shorter $\mathrm{ROH}$ allow for the identification of signatures of selection. In case of the Dalmatian, $F_{\mathrm{ROH} 40}$ 
seems short enough, as with this threshold the a consensus ROH containing SLC2A9 was found. This gene harbors the mutation for hyperuricosuria, which all Dalmatians are afflicted with [22], except for low uric acid (LUA) Dalmatians. By outcrossing with a Pointer, the wild type allele was introduced to a line of Dalmatians [23]. None of those LUA Dalmatians were included in the Beadchip sample. From the length of the $\mathrm{ROH}$ ( $417.597 \mathrm{bp)}$ we can assume the hyperuricosuria mutation became fixed in the Dalmatian $\sim 119$ generations ( 515 years) ago.

The Dalmatians spots are another trait fixed in the breed. One gene responsible for this phenotype is MITF, which causes the extreme white spotting $[24,25]$. The colored spots result from the influence of a ticking locus [25]. Although the trait is fixed, MITF could not be found in any consensus ROH. MITF is located on CFA 20 and stretches from $21,612,927$ to $21,870,578$. It contains 23 Beadchip SNP, which is within the average SNP-density of the Illumina CanineHD BeadChip. Further inspection of the gene with PLINK could not identify consensus ROHs of all 307 animals even with a $\mathrm{ROH}$ threshold of $5 \mathrm{SNPs}, 60 \mathrm{~kb}$ length and 2 missing SNPs. We therefore speculate, that the initial $\mathrm{ROH}$ created by the early trait fixation in the breed, is that old it got broken down over time and is now too small to be detected by our thresholds. This is plausible since the spotting is the main and therefore earliest breed defining trait.

It has already been hypothesized that the hyperuricosuria mutation became fixed in the Dalmatian population due to selection for large and solid pigmented spots [23, 26]. Also it is widely accepted that the extreme white spotting plays a role in CCSD in the Dalmatian [27]. Together, the estimated age of consensus ROHs with genes coding for breed defining traits (hyperuricosuria and deafness), and the connection of those traits with the extreme white spotting, all point to a presumable breed formation about 500 years ago. These assumptions coincide with the earliest documentation of the Dalmatian breed in the 14th century [28].

\section{Conclusions}

In comparison to other dog breeds, the Dalmatian is a rather genetically diverse breed. Pedigree- and genomicbased inbreeding calculation results showed high conformity and therefore prove a good quality of the used pedigree and good reliability of both methods if a high quality dataset is given. In consensus ROHs of the investigated Dalmatian population four genes associated with deafness were identified. Those genes deserve further investigation for their possible contribution to Dalmatian CCSD. The short length of these ROHs indicate an early emergence of variants contributing to congenital hearing loss. This finding may explain the widespread prevalence of CCSD in all Dalmatian lines. Consensus $\mathrm{ROH}$ with genes coding for breed-defining traits point to a breed formation of approximately 500 years ago.

\section{Materials and methods Computation of inbreeding measures based on pedigree data}

ENDOG v4.8 [29] was utilized for the calculations. The whole pedigree encompassed 25.761 animals, including the 313 genotyped animals. A reference population including all animals born in the years 1995-2015, including the genotyped animals, was created.

As a measure of pedigree completeness, the mean equivalent generations (sum of $(1 / 2)^{\mathrm{n}}$ terms over all known ancestors, where $\mathrm{n}$ is the number of generations separating the individual from the ancestor, [30]) were calculated.

The individual inbreeding coefficient $F$ was computed according to Meuwissen and Luo [31]. $\mathrm{F}_{\mathrm{IS}}$ as a part of Fstatistics was calculated for the reference population and Beadchip sample as subpopulations [32]. The approach was $F_{I S} \frac{\tilde{F}-\bar{f}}{1-\bar{f}}$, with $\tilde{F}$ being the mean inbreeding coefficient for the entire metapopulation, an $\bar{f}$ the average coancestry for the subpopulation [33, 34]. Furthermore, we calculated the effective number of founders $f_{e}$ and the effective number of ancestors $f_{a}$ [10]. The effective number of founders is defined as the number of equally contributing founders that are expected to produce the same genetic diversity as the studied population. It is computed as $f_{e}=1 / \sum_{k=1}^{f} q_{k}^{2}$, with $q_{k}$ being the probability of gene origin of the $k$ ancestor $[35,36]$. The effective number of ancestors $f a$ states the minimum number of ancestors explaining the complete genetic diversity of the population. This parameter accounts for the unbalanced reproductive use of founders. The computation is similar to the effective number of founders: $f_{a}=1 / \sum_{j=1}^{a} q_{j}^{2}$ Here $q_{j}$ is the marginal contribution of an ancestor $j$, which is the genetic contribution by an ancestor that is not attributable to the other ancestors chosen before. $\mathrm{N}_{\mathrm{e}}$ was estimated from the individual increase in inbreeding $\Delta F_{i}[18,37]$ and also by the increase in coancestry for all pairs of individuals $j$ and $k$ for the Beadchip sample. The parameter is calculated as following: $\Delta c_{j k}=1-\sqrt[g i+g k 2]{\left.1-c_{j k}\right)}$, with $c_{j k}$ as the inbreeding value of an offspring from $j$ and $k$, and $g_{j}$ and $g_{k}$ are the discrete equivalent generations of individuals $j$ and $k$ [38]. $\Delta \mathrm{F}_{\mathrm{i}}$ is computed as $\Delta F_{i}=1-\sqrt[t-1]{1-F_{i}}$, with $\mathrm{F}_{\mathrm{i}}=$ individual inbreeding coefficient and $\mathrm{t}=$ equivalent complete generations [30]. For the $\mathrm{N}_{\mathrm{e}}$ calculation over the increase in inbreeding the $\Delta \mathrm{F}_{\mathrm{i}} \mathrm{S}$ of the individuals in 
the reference population are averaged and $\overline{N_{\mathrm{e}}}$ calculated as $\overline{N_{\mathrm{e}}}=\frac{1}{2 \overline{\Delta F}}$. This method to estimate $\overline{N_{e}}$ is also called Realized effective population size [39]. The generation intervals were defined as the average age of parents at the birth of their offspring kept for reproduction and were calculated over the four pathways (father-son, motherdaughter, father-daughter and mother-son) [40]. The average coancestries were calculated with PEDIG [41].

\section{Samples and genotyping}

Blood samples of 307 Dalmatians were obtained from the bio-bank of the Institute for Animal Breeding and Genetics at the University for Veterinary Medicine Hannover. The dogs were selected from the birth years 1995 to 2015. Pedigree data of Dalmatians born from 1995 to 2015 as a reference population were obtained from a public database for pedigree books. The $307 \mathrm{Dal}-$ matians which were genotyped on the Illumina CanineHD BeadChip were included and marked separately in the dataset. For genotyping genomic DNA from EDTAblood samples was extracted through a standard ethanol fractionation with concentrated sodiumchloride $(6 \mathrm{M}$ $\mathrm{NaCl})$ and sodium dodecyl sulphate (10\% SDS). The concentration of DNA was adjusted to $50 \mathrm{ng} / \mu \mathrm{l}$ per sample. Genotyping was performed on the Illumina CanineHD BeadChip containing 173,662 SNPs.

\section{Statistical analysis}

The dataset for the estimation of diversity measures consisted of 168,360 SNPs with a genotyping rate $>0.90$ in 307 Dalmatians. 6 Dalmatians did not pass quality control, but were included as "genotyped animals" in the pedigree analysis. For the detection of $\mathrm{ROHs}$ we applied quality control with PLINK v.1.09 [42] and excluded all SNPs from sex chromosomes $(n=5295)$ and SNPs that could not be assigned to a chromosome $(n=523)$ resulting in a reduced dataset of 162,542 autosomal SNPs. We calculated $r^{2}$ as a measure of LD among SNP alleles per chromosome using PLINKv.1.09. The $r^{2}$-values for SNP pairs with distances of $1 \mathrm{~kb}$ to $33.3 \mathrm{Mb}$ were grouped into distance bins of $0.1 \mathrm{Mb}$. For each bin the mean $r^{2}$ values were calculated and the effective population size was estimated as $\mathrm{N}_{\mathrm{e}}=\left(1-\mathrm{r}^{2}\right) /\left(4 \mathrm{cr}^{2}\right)$ with $\mathrm{c}=$ recombination rate in Morgan units [43]. Regarding the distance $c$ between two SNPs we assumed that $100 \mathrm{Mb} \sim 1$ Morgan. The number of generations in the past was estimated as $\mathrm{t}=1 /(2 \mathrm{c})$. The increase in inbreeding was computed as $\Delta \mathrm{F}=1 /\left(2 \mathrm{~N}_{\mathrm{e}}\right)$ [18]. The sliding windows for ROH detection with PLINK v.1.09 contained 10, 20, 30, 40, 50, 65 and 358 SNPs. A ROH in one individual was called if a homozygous stretch contained $10,20,30,40$, $50,65,358$, or more SNPs and extended over 120, 240, 360, 480, 700, 910 or $5012 \mathrm{~kb}[44,45]$. We did not allow for heterozygous SNPs and only for five missing SNP genotypes per 50, 65 and 358 SNP-window, four missing SNP genotypes per $40 \mathrm{SNP}$-window, three per 30 SNPwindow and two for the 20 and 10 SNP-windows [45]. The matching proportions of ROHs overlapping in all Dalmatians were pooled to consensus ROHs. The time of origin of the consensus $\mathrm{ROHs}$ in generations was estimated as 1/(2c) [18]. We used SAS v.9.4 (Statistical Analysis System Institute Inc., Cary, NC, USA) to identify genes that are located in the consensus ROHs. We screened the NCBI database (National Center for Biotechnology Information, U.S. National Library of Medicine) for known genes for common diseases in the Dalmatian, according to [21] and searched for overlaps with consensus ROHs (Table S1). We also identified $\mathrm{ROHs}$ that were partially fixed in the population and therefore common to $50 \%$ or $75 \%$ of all Dalmatians. The inbreeding coefficient $\mathrm{F}_{\mathrm{ROH}}$ for each dog was estimated as the length of all $\mathrm{ROH}$ per threshold in the respective individual divided by the total length of all autosomes covered by SNPs: $F_{R O H}=\sum^{L_{R O H}} /_{L_{A U T O}}$ [46]. We used PLINK v.1.09 to calculate $\mathrm{F}_{\mathrm{IS}}$-values for each individual $i$ as $F_{I S, I}=\left(O_{i}-E_{i}\right) /\left(n S N P_{, I}-E_{i}\right)$, with $E_{i}=$ number of expected homozygous SNPs, $\mathrm{O}_{\mathrm{i}}=$ number of observed homozygous SNPs and $\mathrm{nSNP}_{, \mathrm{i}}=$ number of all SNPs genotyped in the respective individual [47].

PANTHER (Protein Analysis Through Evolutionary Relationships) [48] was used to investigate all genes that are located in the consensus and partially fixed ( $\mathrm{ROHs}$ common to 50 and $75 \%$ of all investigated dogs) ROHs. The gene lists were analyzed with the "functional classification" analysis and the "statistical overrepresentation" test.

For the screening of genes located in the consensus ROHs for important disease-associated genes, we applied a candidate gene list (Table S1). This table contains a list of candidate genes for frequent diseases of the Dalmatian dog, as stated by Bell et al. [21]. A candidate gene search was performed in the NCBI database, and the non-canine candidate genes were transformed into orthologous dog genes with g:Profiler Orthology search [49].

\section{Supplementary information}

Supplementary information accompanies this paper at https://doi.org/10. 1186/s40575-020-00082-y.

Additional file 1: Figure S1. Detail of decay of linkage disequilibria $\left(r^{2}\right)$ between SNP pairs spanning an increasing distance up to $1 \mathrm{Mb}$.

Additional file 2: Figure S2. Ancestral population size of the Dalmatian in the last 10 generations. The effective population size was estimated from the mean $r^{2}$ for the 38 canine autosomes.

Additional file 3: Table S1. Candidate gene list for frequent diseases in the Dalmatian dog according to "The veterinary medical guide to dog and cat breeds" and the NCBI database. 
Additional file 4: Table S2. PANTHER statistical overrepresentation analysis. Gene lists of the genes located in consensus ROH, 50 and 75\% fixed $\mathrm{ROH}$ were analyzed with the overrepresentation analysis tool of PANTHER. The fold enrichment and the $p$-value of the biological processes of the enriched genes are stated.

Additional file 5: Table S3. PANTHER functional classification of genes located in the consensus ROH. Gene lists of genes located in the consensus $\mathrm{ROH}$ depending in the length of said $\mathrm{ROH}$ s were investigated with the PANTHER functional classification tool. The percentage of genes attributed to a particular biological process are stated.

\section{Acknowledgements}

Special thanks go to Jörn Wrede for his assistance with computation and to Juan Pablo Gutiérrez for a helpful tip with ENDOG.

\section{Authors' contributions}

OD designed the work. OD DV carried out analysis and interpretation of data. DV wrote the manuscript. OD JM revised the manuscript. All authors read and approved the final manuscript.

\section{Funding}

Not applicable.

\section{Availability of data and materials}

The datasets used and/or analysed during the current study are available from the corresponding author on reasonable request.

\section{Ethics approval and consent to participate}

All data was extracted from an existing database and the EDTA-blood samples were obtained from our bio-bank of the diagnostic lab. Therefore no animal welfare committee approval was obtained according to the German Animal Welfare Law (released on 05/18/2006, last changes on 03/29/2017). The blood samples were collected and sent in by accredited veterinarians according to the national and international guidelines for animal welfare.

\section{Consent for publication}

Not applicable.

\section{Competing interests}

The authors declare that they have no competing interests.

\section{Received: 2 January 2020 Accepted: 17 March 2020}

Published online: 26 March 2020

\section{References}

1. Nielen ALJ, van der Beek S, Ubbink GJ, Knol BW. Epidemiology: population parameters to compare dog breeds: differences between five dutch purebred populations. Vet Q. 2001;23(1):43-9.

2. Leroy $G$, Verrier $E$, Meriaux JC, Rognon X. Genetic diversity of dog breeds: within-breed diversity comparing genealogical and molecular data. Anim Genet. 2009:40(3):323-32.

3. Wiener P, Sánchez-Molano E, Clements DN, Woolliams JA, Haskell MJ, Blott SC. Genomic data illuminates demography, genetic structure and selection of a popular dog breed. BMC Genomics. 2017;18(1):609.

4. Stern JA, White SN, Meurs KM. Extent of linkage disequilibrium in largebreed dogs: chromosomal and breed variation. Mamm Genome. 2013;24(9): 409-15.

5. Pfahler S, Distl O. Effective population size, extended linkage disequilibrium and signatures of selection in the rare dog breed lundehund. PLoS One. 2015;10(4):e0122680.

6. Alam M, Han Kl, Lee DH, Ha JH, Kim JJ. Estimation of effective population size in the Sapsaree: a Korean native dog (Canis familiaris). Asian Australas J Anim Sci. 2012;25(8):1063-72.

7. Mäki K. Population structure and genetic diversity of worldwide Nova Scotia duck tolling retriever and Lancashire heeler dog populations. J Anim Breed Genet 2010:127(4):318-26.

8. Kardos M, Luikart G, FW A. Measuring individual inbreeding in the age of genomics: marker-based measures are better than pedigrees. Heredity(Edinb). 2015;115(1):63
9. Kirin M, McQuillan R, Franklin CS, Campbell H, McKeigue PM, Wilson JF. Genomic runs of homozygosity record population history and consanguinity. PLoS One. 2010;5(11):e13996.

10. Boichard D, Maignel L, Verrier $E$. The value of using probabilities of gene origin to measure genetic variability in a population. Genet Sel Evol. 1997; 29(1):5.

11. Lutaaya BE, Misztal I, Bertrand J, Mabry J. Inbreeding in populations with incomplete pedigrees. J Anim Breed Genet. 1999;116(6):475-80.

12. Cassell B, Adamec V, Pearson R. Effect of incomplete pedigrees on estimates of inbreeding and inbreeding depression for days to first service and summit milk yield in Holsteins and jerseys. J Dairy Sci. 2003;86(9):2967-76.

13. Suarez B, Reich T, Fishman P. Variability in sib pair genetic identity. Hum Hered. 1979:29(1):37-41.

14. Guo S-W. Variation in genetic identity among relatives. Hum Hered. 1996; 46(2):61-70

15. Stam $P$. The distribution of the fraction of the genome identical by descent in finite random mating populations. Genet Res. 1980;35(2):131-55.

16. Risch N. Application of a recombination model in calculating the variance of sib pair genetic identity. Ann Hum Genet. 1979:43(2):177-86.

17. Bradley D, Fries R, Bumstead N, Nicholas F, Cothran E, Ollivier L, et al. Secondary guidelines for development of National Farm Animal Genetic Resources Management Plans. Roma: Food and Agricultural Organization of United Nations (FAO); 2004

18. Gutiérrez JP, Cervantes I, Molina A, Valera M, Goyache F. Individual increase in inbreeding allows estimating effective sizes from pedigrees. Genet Sel Evol. 2008:40(4):359

19. Gray MM, Granka JM, Bustamante CD, Sutter NB, Boyko AR, Zhu L, et al. Linkage disequilibrium and demographic history of wild and domestic Canids. Genetics. 2009;181(4):1493-505.

20. Keller MC, Visscher PM, Goddard ME. Quantification of inbreeding due to distant ancestors and its detection using dense SNP data. Genetics. 2011; 189:237.

21. Bell J, Cavanagh K, Tilley L, Smith FW. Veterinary medical guide to dog and cat breeds: CRC press; 2012

22. Bannasch D, Safra N, Young A, Karmi N, Schaible RS, Ling GV. Mutations in the SLC2A9 gene cause Hyperuricosuria and Hyperuricemia in the dog. PLoS Genet. 2008;4(11):e1000246.

23. Safra $\mathrm{N}$, Schaible RH, Bannasch DL. Linkage analysis with an interbreed backcross maps Dalmatian hyperuricosuria to CFA03. Mamm Genome. 2006; 17(4):340-5.

24. Baranowska Korberg I, Sundstrom E, Meadows JR, Rosengren Pielberg G, Gustafson U, Hedhammar A, et al. A simple repeat polymorphism in the MITF-M promoter is a key regulator of white spotting in dogs. PLoS One. 2014;9(8):e104363.

25. Little CC. The inheritance of coat color in dogs The inheritance of coat color in dogs; 1957

26. Schaible R. Linkage of a pigmentary trait with a high-level of uric-acid excretion in dalmation dog. Genet. 1976;83:S68.

27. Stritzel S, Wohlke A, Distl O. A role of the microphthalmia-associated transcription factor in congenital sensorineural deafness and eye pigmentation in Dalmatian dogs. J Anim Breed Genet. 2009; 126(1):59-62

28. Bauer $M$, Lemo $N$. The origin and evolution of Dalmatian and relation with other croatian native breeds of dog. Rev Med Vet. 2008;159:618-23.

29. Gutiérrez JP, Goyache F. A note on ENDOG: a computer program for analysing pedigree information. J Anim Breed Genet. 2005;122(3):172-6.

30. Maignel L, Boichard D, Verrier E. Genetic variability of French dairy breeds estimated from pedigree information. Interbull Bulletin. 1996;14:49.

31. Meuwissen THE, Luo Z. Computing inbreeding coefficients in large populations. Genet Sel Evol. 1992:24(4):305-13.

32. Wright S. Evolution and the genetics of populations. In: Variability within and among populations, vol. 4. Chicago: University of Chicago Press; 1978.

33. Caballero A, Toro MA. Interrelations between effective population size and other pedigree tools for the management of conserved populations. Genet Res. 2000;75(3):331-43.

34. Caballero A, Toro MA. Analysis of genetic diversity for the management of conserved subdivided populations. Conserv Genet. 2002;3(3):289-99.

35. Lacy RC. Analysis of founder representation in pedigrees: founder equivalents and founder genome equivalents. Zoo Biology. 1989;8(2):111-23.

36. James J. Computation of genetic contributions from pedigrees. Theor Appl Genet. 1972;42(6):272-3. 
37. Gutiérrez J, Cervantes I, Goyache F. Improving the estimation of realized effective population sizes in farm animals. J Anim Breed Genet. 2009;126(4): 327-32.

38. Cervantes I, Goyache F, Molina A, Valera M, Gutiérrez J. Estimation of effective population size from the rate of coancestry in pedigreed populations. J Anim Breed Genet. 2011;128(1):56-63.

39. Cervantes I, Goyache F, Molina A, Valera M, Gutiérrez JP. Application of individual increase in inbreeding to estimate realized effective sizes from real pedigrees. J Anim Breed Genet. 2008;125(5):301-10.

40. James J. A note on selection differential and generation length when generations overlap. Anim Sci. 1977;24(1):109-12.

41. Boichard D, editor. PEDIG: a fortran package for pedigree analysis suited for large populations. Proceedings of the 7th world congress on genetics applied to livestock production. Montpellier; 2002.

42. Purcell S, Neale B, Todd-Brown K, Thomas L, Ferreira MA, Bender D, et al. PLINK: a tool set for whole-genome association and population-based linkage analyses. Am J Hum Genet. 2007:81:559.

43. Sved JA. Linkage disequilibrium and homozygosity of chromosome segments in finite populations. Theor Popul Biol. 1971;2(2):125-41.

44. Purfield DC, Berry DP, McParland S, Bradley DG. Runs of homozygosity and population history in cattle. BMC Genet. 2012;13:70.

45. Howrigan DP, Simonson MA, Keller MC. Detecting autozygosity through runs of homozygosity: a comparison of three autozygosity detection algorithms. BMC Genomics. 2011;12(1):460.

46. McQuillan R, Leutenegger A-L, Abdel-Rahman R, Franklin CS, Pericic M, Barac-Lauc $L$, et al. Runs of Homozygosity in European populations. Am J Hum Genet. 2008;83(3):359-72.

47. Browning BL, Browning SR. A unified approach to genotype imputation and haplotype-phase inference for large data sets of trios and unrelated individuals. Am J Hum Genet. 2009;84(2):210-23.

48. Mi H, Muruganujan A, Ebert D, Huang X, Thomas PD. PANTHER version 14: more genomes, a new PANTHER GO-slim and improvements in enrichment analysis tools. Nucleic Acids Res. 2018;47(D1):D419-D26.

49. Raudvere U, Kolberg L, Kuzmin I, Arak T, Adler P, Peterson H, et al. G:profiler: a web server for functional enrichment analysis and conversions of gene lists (2019 update). Nucleic Acids Res. 2019;47(W1):W191-W8.

\section{Publisher's Note}

Springer Nature remains neutral with regard to jurisdictional claims in published maps and institutional affiliations.

Ready to submit your research? Choose BMC and benefit from:

- fast, convenient online submission

- thorough peer review by experienced researchers in your field

- rapid publication on acceptance

- support for research data, including large and complex data types

- gold Open Access which fosters wider collaboration and increased citations

- maximum visibility for your research: over $100 \mathrm{M}$ website views per year

At $\mathrm{BMC}$, research is always in progress.

Learn more biomedcentral.com/submissions 